
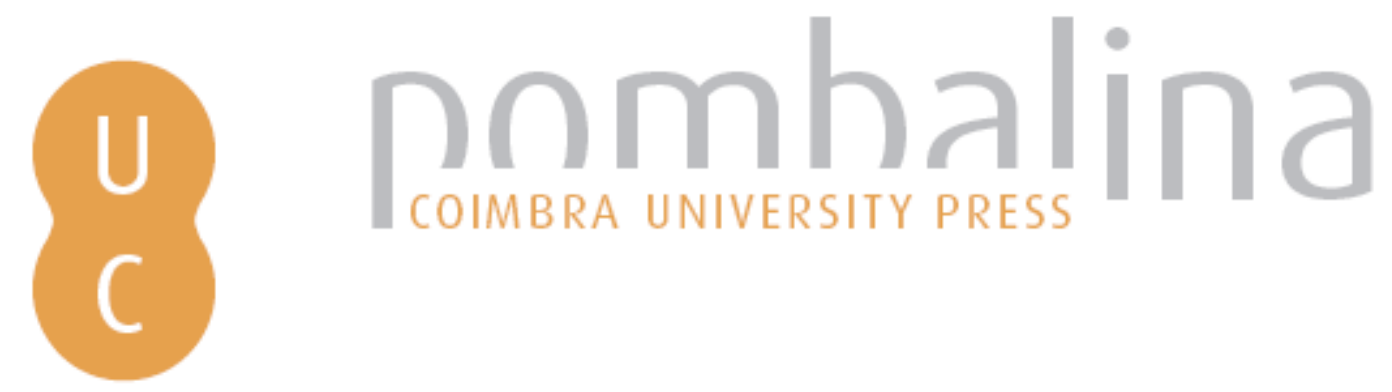

\title{
André de Resende, um novo Alberti: um ideólogo entre o Princeps e o Architectus na recuperação da Vrbs romana de Évora (1531-1537)
}
Autor(es):
Abreu, Susana Matos
Publicado por: Associação Portuguesa de Estudos Clássicos; Centro de Estudos
persistente:
URI:http://hdl.handle.net/10316.2/31563
DOI:
DOI:http://dx.doi.org/10.14195/978-989-8281-69-2_19
Accessed : $\quad$ 26-Apr-2023 11:42:41

A navegação consulta e descarregamento dos títulos inseridos nas Bibliotecas Digitais UC Digitalis, UC Pombalina e UC Impactum, pressupõem a aceitação plena e sem reservas dos Termos e Condições de Uso destas Bibliotecas Digitais, disponíveis em https://digitalis.uc.pt/pt-pt/termos.

Conforme exposto nos referidos Termos e Condições de Uso, o descarregamento de títulos de acesso restrito requer uma licença válida de autorização devendo o utilizador aceder ao(s) documento(s) a partir de um endereço de IP da instituição detentora da supramencionada licença.

Ao utilizador é apenas permitido o descarregamento para uso pessoal, pelo que o emprego do(s) título(s) descarregado(s) para outro fim, designadamente comercial, carece de autorização do respetivo autor ou editor da obra.

Na medida em que todas as obras da UC Digitalis se encontram protegidas pelo Código do Direito de Autor e Direitos Conexos e demais legislação aplicável, toda a cópia, parcial ou total, deste documento, nos casos em que é legalmente admitida, deverá conter ou fazer-se acompanhar por este aviso.

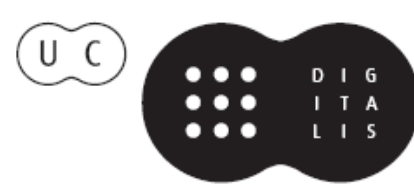




\section{Espaços e Paisagens}

Antiguidade Clássica

e Heranças Contemporâneas

Vol. III

Francisco Oliveira, Jorge Oliveira e Manuel Patrício

IMPRENSA DA UNIVERSIDADE DE COIMBRA 


\title{
André De Resende, um NOvo Alberti? \\ UM IDEÓLOGO ENTRE O PRINCEPS E O ARCHITECTUS, NA RECUPERAÇÃO DA VRBS ROMANA DE ÉVORA (1531-1537)
}

\author{
Susana Matos Abreu \\ Faculdade de Letras da Universidade do Porto / CEPESE
}

\begin{abstract}
André de Resende as a new Alberti?: an ideologist between the Princeps and the Architectus in the requalification of the Roman Vrbs of Évora (Portugal 1531-1537).
\end{abstract}

In 1531-37, when the Portuguese court moved temporary from Lisbon to Évora, this city became a stage of bold urban and architectural renovations. King John III (1521-57) commissioned there a series of improvements to host the court, which reorganized and clarified the Roman urban tissue of the city while restoring some of its ancient monuments. His plan, full of symbolic meaning, used the rhetorical power of the Roman ruins to support the increasing absolutism of his political agenda, accordingly to Alberti's ideas about the power of the ancient remains as instruments to the ruler.

The action of the humanist André the Resende (1500-73) as an expert on antiquities and archaeology is noticeable during this period, as he informs us to have been responsible for the monarch's decision to restore the supposed Roman aqueduct of Água de Prata. Moreover, one can suspect him to have guided the whole royal urbanistic, and architectural program in someway, as he also tells us that the king commissioned him the translation of the De re aedificatoria by Leon Battista Alberti (1404-72), just after having finished two other books on aqueducts at his request.

Our approach goes deeper into this conjecture, analysing a narrative that Resende wrote about the history of the city of Évora, focused on its antiquities - the Historia da Antiguidade da Cidade de Évora (Évora: André de Burgos, 1552). In this text, we can find enough potential inspiration to set the guidelines that transformed the city. The idea gets its strength when noticing some thematic and methodological similarities that exist between the Historia and its literary models found in the writings of Flavio Biondo da Forlì (1392-1463). This author, a humanist and archaeologist, was responsible - together with Alberti and others - for setting up the humanistic program of the instauratio imperii of Rome, and for inciting the subsequent renovatio urbis that took place during the pontificate of Nicholas V (1447-1455). It is possible to find striking parallels, both textual and material, between the royal plan designed for Évora as revealed by Resende's Historia and the former papal plan intended to restore the ancient grandeur of the Roman vrbs as described by Giannozzo Manetti (1396-1459). They set forth the idea that Resende acted in Évora as a counsellor to King John III, advising him about the redesign of the city's public space while taking the modern city of Rome as a model. But could this translator of the De re aedificatoria also have acted in Évora as a new Alberti, i. e., as the mediator between the princeps and the architectus, which had been both a counsellor to pope Nicholas V and a mentor to the papal architect Bernardo Rosselino? If so, Resende would probably be following the example of Alberti in Rome during the Quattrocento, as an expert on antiquities and urbanism/architecture, helping to transform the city of Évora into the new capital of the realm. 
Keywords: heritage and politics, heritage and politics, Renaissance architect, Renaissance urban requalification.

Palavras-chave: memória urbana, urbanismo renascentista, requalificação urbana e modelos literários, vestígios arqueológicos e identidade local.

Entre 1531-37, quando a cidade de Évora acolheu a corte portuguesa, o rei D. João III (1521-57) empreendeu um vasto projecto de requalificação daquela cidade, então convertida em cabeça provisória do reino. A reunião de artistas e intelectuais cedo promoveu ali um clima de euforia em torno do restauro dos valores clássicos acompanhando o florescimento do Humanismo; e o programa político joanino, tendencialmente absolutista, foi então moldado à imagem imperial de Augusto - o que derivou no cariz antiquário de tais melhoramentos (R. Moreira 1991 198-405).

A acção do humanista André de Resende (1500-73) destaca-se em Évora durante este período enquanto arqueólogo e perito em antiguidades, estando há muito associada a tal reforma urbana. É o próprio quem afirma ter convencido o monarca a restaurar um suposto aqueduto romano com o auxílio de "dous livros dos aqueductos" que escrevera a pedido do rei (A. Resende 1783: biij), certamente para dar apoio técnico às obras. A sua acção, que já por aqui se adivinha incisiva como consultor sobre hidráulica romana - tais livros deveriam tratar-se da tradução do De Aquaeductibus de Frontinus, que andava apensa ao "Vitrúvio" de 1511 -, sugere ter chegado à de conselheiro régio acerca dos restantes empreendimentos face à notícia, que igualmente dá, de o rei lhe ter encomendado ainda um "livro de architectura" (A. Resende 1783 a.v. v) - este seguramente a tradução do De re aedificatoria (Florença: Niccolo di Lorenzo Alamani, 1486) de Leon Battista Alberti (1404-72), que aparece listada no seu testamento.

O presente estudo aprofunda esta suspeita por análise da fonte de tais notícias - o texto da Historia da Antiguidade da Cidade de Évora (Évora: André de Burgos, 1552) -, a única também acerca da participação do autor na reforma da cidade. Aqui se detectam paralelismos temáticos e metodológicos com certa literatura de Flavio Biondo da Forlì (1392-1463), homem de letras e arqueólogo que foi um dos arautos do programa da instauratio imperii no pontificado de Nicolau V (1447-55). Sabe-se que as investigações arqueológicas de Biondo, registadas em tal literatura, terão ajudado outros, tais como o mencionado Alberti, a enformar o subsequente programa de renovatio urbis destinado a dar lustro à esmaecida Roma imperial enquanto capital da Cristandade (C. Smith; J. O'Connor 2006). E este, por sua vez, encontraria em tal tarefa a ocasião de reflectir acerca do valor da Arquitectura como instrumento de poder, o que registará do De re aedificatoria oferecido a Nicolau V. O jogo de espelhos - ideológico, literário e arquitectónico - que sugerimos existir na Historia de Resende, reflecte o plano urbanístico papal quatrocentista e o plano régio delineado para Évora, questionando assim que o autor, além de gloriar a cidade pelas suas "antiguidades" enquanto arqueólogo, tenha ainda actuado como mediador entre o princeps e o architectus. Nisto se 
poderia equiparar a Alberti na sua actuação enquanto ideólogo do projecto urbanístico nicolino - o que aqui propomos.

1. De Roma a Évora: modelos literários da Historia

A Historia da Antiguidade da Cidade de Évora trata-se do primeiro texto que André de Resende dedicou às antiguidades nacionais, aí se compilando, naquele que é também o primeiro ensaio peninsular sobre antiguidades e monografia de um município ibérico, o rol dos achados arqueológicos feitos pelo humanista na cidade e no seu aro. Encomendada pelas autoridades locais e redigida entre 1541-47 (já após o regresso da corte a Lisboa), a Historia trata-se ainda de um hábil manifesto político que pretende convencer o monarca a retornar a Évora e a consagrá-la como capital do reino. Para tal, André de Resende apoia a descrição das "antiguidades" na história da cidade, cuja confecção, dourando os seus pergaminhos de antiguidade, procura afagar as expectativas de D. João III de revestir-se de dignidade "à romana" (I. Sousa 1993 18-23, 54-68).

Já foi notado que teria sido concretamente no exemplo de Roma que André de Resende se terá inspirado para compor o texto (S. Abreu 2004 4-6). O autor divide-o em três partes de acordo com a concepção renascentista tripartida da História - Antiga, Medieval e Moderna - explorada por autores como Flavio Biondo da Forlì, que foi dos primeiros a utilizá-la a propósito da renovatio imperii. Como ele, Resende privilegia o esplendor romano da cidade e, após deter-se brevemente sobre o período de decadência gótica e moura, enaltecelhe a glória presente pela instauração da fé cristã. Para isso recorre a exempla: Sertório V, caudilho dos Lusitanos, é o herói do domínio romano; S. Manços, protoapóstolo que foi primeiro bispo de Évora, e Giraldo-Sem-Pavor, bravo que a reconquistou aos mouros, exaltam o passado cristão. Nesta polaridade temática Resende procura, à semelhança do humanista de Nicolau V, usar o prestígio do passado latino da cidade para realçar o presente, sem deixar de afirmar a superioridade deste último tempo por via da fé (S. Abreu 2004 6). Os vestígios arqueológicos, oscilando entre antiguidades pagãs e mirabilia cristãs, são apresentados no texto como provas materiais de veracidade factual (I. Sousa 1993 37-45). A Historia de Resende parece assim alimentar-se directamente da Roma instaurata (1444-46), onde Biondo, autor de pioneiras inventariações e descrições de "antiguidades", recorre à arqueologia para legitimar a Roma papal como continuadora da Civitas Aeterna imperial. E na Roma triumphans (1452-59) Biondo apresenta, poeticamente, uma narrativa histórica da cidade igualmente sustentada por evidências arqueológicas, a que 
a Historia de Resende se aproxima pelos objectivos, o temário e o estratagema ${ }^{1}$ (S. Abreu 2004 6).

2. O paradigma romano de renovação urbana de Évora

$\mathrm{O}$ paralelo que por aqui se estabelece entre os objectivos da Historia e os da renovatio imperii, ambos ligados na sua origem ao ideário imperial, legitimam que, em Roma como em Évora, se tenha adoptado uma estética classicizante nos novos empreendimentos urbanísticos e arquitectónicos. Mas também os modelos textuais da Historia apontam para Roma enquanto paradigma formal dos investimentos feitos em Évora: o texto de Resende parece cifrar a organização simbólico-topológica da cidade joanina na história da urbe, procurando estabelecê-la, em traços muito gerais, sobre a imagem da Roma moderna.

Para se compreender tal aderência ao paradigma não basta relembrar as qualidades do lugar de Évora tal como o autor as descreve - as colinas que rodeiam a cidade, os arredores férteis ou a relativa proximidade ao mar, mas também os malefícios que a escassez de água lhe trazia, como se lê em Vitrúvio, Frontino e Alberti a respeito de Roma. Importa ainda atender ao edificado que, segundo Resende, documenta o passado da cidade. Neste ponto, a acção de Sertório V, descrito como o verdadeiro fundador da urbe, revela-se fundamental. No seu tempo teriam sido construídas três grandes obras, cujos vestígios arqueológicos Resende identifica: 1 . as "casas" (ou palácio) onde o herói assentou a coorte; 2 . as muralhas da cidade; 3 . e o aqueduto (Resende 1783 9-10v); elenco que, pese embora magro, decreta o nascimento de Évora enquanto centro político, militar e cívico. É neste passo da Historia que o moderno arquétipo romano nas obras de Évora mais se evidencia - e, com ele, também a intuição de Resende acerca do altíssimo significado do modelo morfológico da Vrbs romana fixado na Civitas renascentista papal.

Salvaguardando diferenças de escala, verifica-se que o programa eborense se ilumina em concreto pelo vasto plano de "restauros" empreendido por Nicolau V, tal como aparece descrito no Liber Secundus de Vita ac Gestis Nicolai Quinti de Gianozzo Manetti (1396-1459) (S. Abreu 2004 6-9). Aqui, Manetti destaca os cinco grandes vectores que orientaram o plano: 1. a reparação da muralha de Aureliano; 2. a reabilitação do aqueduto de Acqua Vergine; 3 . o restauro dos melhores edifícios da Antiguidade e seu resgate ao culto cristão; 4. a construção do Borgo Vaticano, com o palácio papal; 5. e a edificação de uma nova igreja de S. Pedro (do que ficou apenas a intenção) ${ }^{2}$. Além do registo economicista e utilitário do plano, este pautou-se por rara inteligência

${ }^{1}$ Existem na B.P.E.: F. Biondo (1548), Roma ristaurata, et italia illustrata. Veneza; F. Biondo (1548), Roma trionfante. Veneza; F. Blondus (1503), De Roma Instaurata [...] de Italia Illustrata. Veneza, e ainda um Mirabilia vrbis Romae (1535). Roma.

2 "Cinque grandi emprese erano fitte nella mente del papa: il rassettamento delle mura urbane, degli acquedotti e ponti, il restauro delle 40 chiese cosidette stazionali, la nuova costruzione del Borgo Vaticano, del palazzo papale e della chiesa di S. Pietro" (apud F. Borsi 1973 37). 
do facto urbano enquanto estratificação da memória e repositório de sentidos simbólicos - ainda evidente no melhoramento da rede viária clarificando o antigo traçado romano, ou na limpeza urbana das construções parasitas que desvirtuavam os principais edifícios antigos. Os elementos destacados por Manetti denotam atenção ao valor da obra singular no seio do tecido edificado anónimo, tal como postulado por Alberti no De re aedificatoria (Argan 1998); e ainda atendem ao carácter semiológico das estruturas a que hoje chamaríamos "monumentos históricos" (F. Choay 1997; F. Choay 2000 38) enquanto marcos fundamentais do urbanismo que se pretendia realçar. Assim, não foi somente a morfologia da Vrbs que se reencenou na Roma de Nicolau V, mas também a da Civitas, estrutura material complexa que representa o Estado e o cidadão, bem como a teia de relações entre um e outro.

A hermenêutica do texto resendiano permite fazer uma leitura do espaço joanino de Évora semelhante à desta lição: também aqui os principais investimentos podem ser descritos como uma série de melhoramentos que clarificam o antigo traçado da $V r b s$ de herança romana e valorizam as estruturas singulares desse passado, à boleia de cujos sentidos simbólicos se criam novas polaridades monumentais. É concretamente da Vita de Nicolau $V$ que nos parece decalcar-se a lista dos principais investimentos: o palácio, a muralha e o aqueduto; no plano prático, foram precisamente as antiguidades sertorianas listadas na Historia, saliências simbólicas dos poderes político, militar e cívico, que constituíram os mais importantes pontos de intervenção valorativa e de restauro: 1. o repristinamento das "casas" (ou palácio) de Sertório; 2. a revalorização da muralha romana (que foi limpa de construções espúrias); 3. a reposição do suposto aqueduto romano em funcionamento. Todas estas pontuações monumentais foram articuladas com o centro cívico da época - a Praça do Giraldo -, relacionando-se com ele de modo periférico, isto de feição que se diria acompanhar a narrativa histórica de Resende por acentuar a importância romana da urbe, sem todavia deixar de conceder primazia (simbólico-topológica) ao presente (que era cristão). A obra do palácio - os actuais Paços do Concelho - acompanhou-se da regularização do traçado da praça fronteira, a qual foi então rebaptizada como "Praça de Sertório" ancorando toponimicamente o edifício no passado latino da urbe confeccionado pela Historia. As operações de desimpedimento da cerca romana, ali bem perto, deixaram a nu alguns troços desta estrutura em memória da sua antiga grandeza, concorrendo para o mesmo efeito que terá tido, noutra escala e repercussões na memória colectiva, a restituição do Aqueduto da Água de Prata à sua glória primeva em 1537. Os restantes itens do programa de Manetti não teriam escapado ao plano resendiano no âmbito de uma reconstrução do passado paleocristão da cidade ${ }^{3}$ : ainda em tempo de permanência da corte em Évora, Resende fez campanhas arqueológicas nos

${ }^{3} \mathrm{O}$ restante programa papal teve paralelo em Évora: a Sé - equivalente a S. Pedro enquanto sede do poder religioso - fora beneficiada entre 1522-25 por D. João III, que em 1528 a dotou de ornamentos. A sua contrapartida civil - os paços reais, equivalentes do Vaticano - foram alvo de vastos melhoramentos antes de a corte se instalar na cidade, em 1525. 
arredores do burgo para identificar os vestígios da primitiva basílica de S. Manços construída pelo santo, talvez na mira de que D. João III a beneficiasse. Certo é, a Historia instigará à reedificação da pequena ermida de S. Vicente (mártir documentado na Historia), que o autor supõe ter identificado nas imediações da Sé (P. Gomes 2001 36-39). Esta seria uma medida simbólica equivalente à de restauro dos melhores edifícios romanos e seu resgate para o culto cristão, tal como em Roma se fizera por competentes restauros do arquitecto Bernardo Rosselino aconselhados por Alberti - e, aqui como ali, realizados com avisado conhecimento da arquitectura paleocristã. À acção nestes "monumentos históricos" não faltou sentido de oportunidade tal como avisava Alberti no De re aedificatoria: o palácio, a muralha e o aqueduto estabelecem entre si uma triangulação simbólica justificando o nascimento do facto urbano, em raciocínio certamente estimulado pela actuação deste humanista e arquitecto na Roma nicolina.

3. André de Resende, um ideólogo entre o princeps e o architectus?

Por tudo isto, a compilação das "antiguidades" de Évora e a confecção do seu mítico passado na Historia - tarefas realizadas enquanto decorriam as obras da cidade - constituem um forte elo conceptual que une André de Resende a Alberti. Tal como esta figura explorou e documentou a arquitectura, a topografia e a história de Roma empenhado na renovatio imperii, também Resende terá agido como arqueólogo e escritor para, talvez enquanto ideólogo, enformar o programa régio de renovação da cidade de Évora "à antiga". Não existe, porém, qualquer suspeita de que tenha actuado como verdadeiro architectus tal como teorizara Alberti; mas não será que este tradutor português do De re aedificatoria se possa ter inspirado concretamente naquela figura para moldar a sua própria actuação em Évora? Enquanto tradutor de tratados técnicos e de Arquitectura, Resende assemelha-se a um novo Alberti porquanto tentando adquirir os conhecimentos científicos e a teoria arquitectural dos Antigos que lhe faltavam para assim ajudar a cumprir o programa de reforma urbana.

As considerações aqui tecidas levantam a necessidade de se interpelar as relações entre Resende e os artistas ao serviço do programa edílico joanino all'antica, nomeadamente com o arquitecto régio Miguel de Arruda e o escultor Nicolau Chanterene. Obras como a do palácio "de Sertório" ou a fonte que em tempos rematou o aqueduto em frente do palácio real (ambas de desenho e cinzel de Chanterene), e, sobretudo, a Igreja de N. Sra. da Graça (construída e ornamentada por Arruda e Chanterene), vêm alimentando a suspeita da participação de Resende nos densos programas humanísticos de que são eivadas. A fachada da igreja da Graça, particularmente, porque talvez destinada a panteão real e por exibir um programa iconográfico digno de um temple-of-fortune (R. Moreira 1991 364-405) -, sugere uma colaboração estreita entre Resende e o rei, semelhante à que se estabeleceu em Rimini entre Alberti e o poderoso Frederico Malatesta na sua intenção de representar-se publicamente "à antiga". Neste episódio (melhor conhecido que o antecedente de Roma), Alberti elaborou o desenho arquitectónico de um 
panteão sobre arrojado programa iconográfico, mediando assim as intenções daquele princeps e os executantes da obra: o arquitecto Agostino de Duccio (encarregue dos trabalhos de construção) e o escultor Matteo de'Pasti (autor da delicada escultura monumental). De facto, também tudo permite que, em Évora, Resende se tenha colocado na posição de mediador entre o dono da obra e os seus artistas, tal como Alberti terá mediado o papa Nicolau V e o arquitecto Bernardo Rosselino (o principal braço executor do projecto de Roma) - o que estudos futuros deverão indagar.

\section{Bibliografia}

S. Abreu (2004), "De Roma a Évora, com André de Resende: Cidade e 'Património' na História da Antiguidade da cidade de Évora", in @pha.Boletim 2. http:// www.apha.pt/boletim/boletim2/default.htm.

G. Argan ( $\left.{ }^{4} 1998\right)$, "O tratato De Re Aedificatoria", in História da Arte como História da Cidade. São Paulo.

F. Borsi (1973), Leon Battista Alberti. Milano.

S. Borsi (2009), Nicolò V e Roma. Alberti, Angelico, Manetti e un grande piano urbano. Firenze.

M. Carpo (1998), Architecture in the Age of Printing. Cambridge, Massachusetts; London.

F. Choay, (1997), The Rule and the Model. Cambridge, Massachussetts.

F. Choay (2000), A Alegoria do Património. Lisboa.

R. Moreira (1991), A Arquitectura do Renascimento no Sul de Portugal. Lisboa.

A. Resende (1783), Historia da antiguidade da Cidade de Euora. Lisboa.

I. Sousa (1993), André de Resende e a História da Antiguidade da Cidade de Évora. Estarreja. 